\title{
Description of a Selection Method Highly Cytotoxic for Cystinotic Fibroblasts but not Normal Human Fibroblasts
}

\author{
Ronald L. Pisoni, ${ }^{1}$ Rosemary M. Lemons, ${ }^{1}$ Karen M. Paelicke, ${ }^{1}$ and Jess G. Thoene ${ }^{1,2}$ \\ Departments of 'Pediatrics and ${ }^{2}$ Biological Chemistry, The University of Michigan Medical School, Ann Arbor, Michigan \\ 48109-2029
}

Received 16 November 1990 - Final 11 November 1991

\begin{abstract}
Nephropathic cystinosis is an inherited disorder characterized by a high intralysosomal accumulation of cystine due to a defect in lysosomal cystine transport. Cystine can be specifically loaded into the lysosomal compartment of intact cells by incubating cells with cystine dimethyl ester (CDME). We have applied this methyl ester loading technique to develop a selection method that is highly cytotoxic for cystinotic fibroblasts but not normal human fibroblasts and that is based on the inherent differences in lysosomal cystine transport activity of normal and cystinotic fibroblasts. Thus, only 0-0.03\% of fetal cystinotic fibroblasts survive exposure to $2 \mathrm{mM} C D M E$ for $20 \mathrm{~min}$ whereas $70-80 \%$ of normal fetal fibroblasts survive these same conditions. Following transfection of cystinotic fibroblasts with normal human genomic DNA or CDNA, this CDME selection method can be used to select for those cells that have been transformed to the normal phenotype and thus aid in the identification of the gene coding for the lysosomal cystine transport protein.
\end{abstract}

\section{INTRODUCTION}

Nephropathic cystinosis is an autosomal recessively inherited disease characterized by a high intralysosomal accumulation of the amino acid, cystine, which results from a defect in lysosomal cystine transport. Three different forms of cystinosis have been characterized clinically: infantile nephropathic, late-onset, and benign (1). A major step in understanding cystinosis and its various forms on a molecular basis will be to isolate and analyze the gene coding for the lysosomal cystine transport protein. Thus far, the lysosomal cystine transport protein has not been physically isolated, chemically labeled, nor have specific antibodies made against it. Consequently, many of the strategies for isolating mammalian genes can not be applied effectively to identify the lysoso- mal cystine transport protein gene because of an inability to make the specific probes necessary to identify this gene. We have exploited the difference in lysosomal cystine transport activity between normal and cystinotic fibroblasts to develop a selection method cytotoxic for cystinotic fibroblasts but not normal fibroblasts. Following the transfection of cystinotic fibroblasts with vectors containing normal human genomic DNA or cDNAs, this method should greatly aid isolation of cystinotic fibroblasts stably transformed to the normal phenotype and, in conjunction with known methods for gene rescue, assist in identification of the lysosomal cystine transport gene.

\section{MATERIALS AND METHODS}

Diploid fibroblast cultures were derived from skin biopsies of patients with nephro- 
pathic cystinosis or purchased from the Human Genetic Mutant Cell Repository. The cystinotic heterozygote fibroblast cell line derived from the parent of the donor of the SV40-transformed cystinotic cell line (GM02894) was kindly provided by Dr. Jerry Schneider of the University of California, San Diego. Fibroblasts were grown in Coon'smodified Ham's F12 medium (Gibco), supplemented with $10 \%(\mathrm{v} / \mathrm{v})$ fetal bovine serum and incubated at $37^{\circ} \mathrm{C}$ in a humidified incubator flushed with an air- $\mathrm{CO}_{2}$ (19:1) mixture. Selection assays were performed with confluent monolayers of human fibroblasts in $60-\mathrm{mm}$ culture dishes. Cells were washed once with PBS and then placed in medium containing $10 \%$ fetal calf serum and cystine dimethyl ester (Sigma) for the indicated time interval. The plates were then washed once with PBS, harvested by trypsin treatment, a portion of the cells was counted with a model $Z_{\mathrm{f}}$ Coulter counter, and the remaining cells were replated for cell viability studies.

Cell viabilities were determined by a $4-\mathrm{h}$ cell attachment assay, a colony-forming ability assay, or by incorporation of $\left[{ }^{14} \mathrm{C}\right] \mathrm{amino}$ acids into cellular proteins. In the cell attachment assay, cells were trypsinized after CDME selection and allowed to reattach onto $60-\mathrm{mm}$ culture dishes for $4 \mathrm{~h}$ at $37^{\circ} \mathrm{C}$ in culture medium containing $10 \%$ fetal bovine serum. Each dish was then washed twice with PBS, retrypsinized, and the cells recovered at this point were counted. The number of cells recovered from the control plates, which were not exposed to CDME, was considered as $100 \%$ viable. The number of cells recovered under each test condition was expressed as a percentage of this control. The colonyforming ability assay was performed by exposing fibroblasts to cystine dimethyl ester for 10 or $20 \mathrm{~min}$ at $37^{\circ} \mathrm{C}$. Cells were then washed, trypsinized, a portion of the cells counted, and the remaining cells plated in complete medium containing $10 \%$ fetal bovine serum at dilutions great enough to give rise to individual colonies. Cells were allowed to grow for 7-10 days at which time individual colonies were stained with $0.3 \%$ crystal violet for counting as described by Liu et al (2). In the $\left[{ }^{14} \mathrm{C}\right]$ amino acid incorporation method of determining cell viability, cells treated with CDME were trypsinized, replated in $60-\mathrm{mm}$ culture dishes in medium containing $10 \%$ fetal bovine serum and $\left[{ }^{14} \mathrm{C}\right]$ amino acids (Dupont-NEN), and then allowed to attach and grow for $20 \mathrm{~h}$ at $37^{\circ} \mathrm{C}$. The plates were washed three times with PBS and cells were harvested. Cell radioactivity was determined by counting an aliquot of the total cell suspension in CytoScint fluor (ICN) in a Beckman LS $100 \mathrm{C}$ scintillation counter.

Since CDME displays significant hydrolysis when incubated in aqueous solutions for prolonged periods of time, CDME solutions were prepared fresh on the day of the experiment, immediately before use, by adding the appropriate quantity of powdered cystine dimethyl ester to culture medium containing $10 \%$ fetal bovine serum, adjusting the final $\mathrm{pH}$ to 7.2 with $\mathrm{NaOH}$, followed by sterilization through a $0.22-\mu \mathrm{m}$ filter.

\section{RESULTS AND DISCUSSION}

We used the methyl ester loading technique (2-4) to exploit the known difference in lysosomal cystine transport activity between normal and cystinotic fibroblasts $(5$, 6) as the basis for the development of this selection method. Previous studies have shown that the abnormal storage of free cystine within cystinotic fibroblasts is confined to the lysosomal compartment (7-9). Cystine can be specifically loaded into lysosomes of intact cells by incubation with cystine dimethyl ester (CDME) which, at pH $7-8$, readily traverses cell membranes and is then converted to cystine within the lysosome by esterases (10-13). We measured the cystine content of cystinotic fibroblasts after incubation with $20 \mathrm{mM}$ CDME and found that 
the lysosomal cystine content increases about fivefold during a $10-\mathrm{min}$ incubation period (Fig. 1A). As the lysosomal cystine content increases, cell survival decreases such that after a $10-\mathrm{min}$ exposure to $20 \mathrm{mM}$ CDME less than $1 \%$ of cystinotic fibroblasts remain
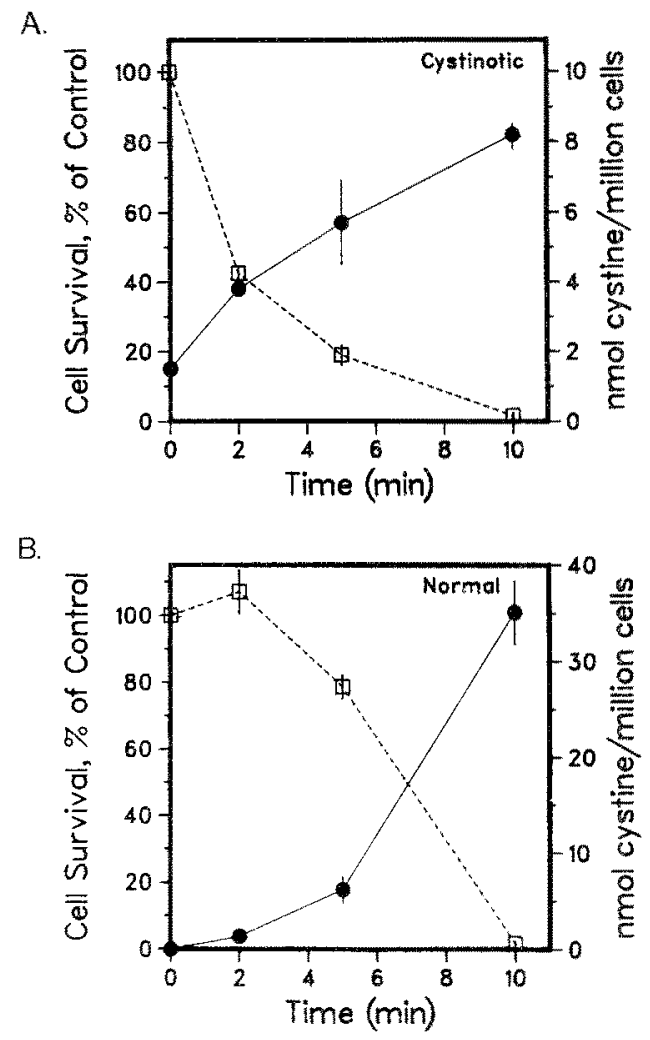

Fig. 1. Effect of $20 \mathrm{mM}$ CDME on the survival and cystine content of cystinotic and normal fetal fibroblasts. The 60-mm confluent plates of cystinotic $(A)$ or normal (B) fetal fibroblasts were incubated at $37^{\circ} \mathrm{C}$ for $0,2,5$, or $10 \mathrm{~min}$ in culture medium containing $20 \mathrm{mM}$ CDME. The plates were then washed twice with PBS, trypsinized for $5 \mathrm{~min}$, and cells harvested and counted. Half the cells were replated into culture medium containing $10 \%$ fetal calf serum and allowed to attach for $4 \mathrm{~h}$ at $37^{\circ} \mathrm{C}$. The remaining cells were pelleted, sonicated, and resuspended in $10 \mathrm{mM}$ sodium phosphate, pH 7.5, buffer containing $5 \mathrm{mM} \mathrm{N}$-ethylmaleimide for assay of cystine content (-) by the cystine binding protein assay (15). After $4 \mathrm{~h}$, the plated cells were harvested by trypsinization and counted to determine the percent survival $(\square-\square)$. The results shown are an average of duplicate determinations with the variation indicated by the vertical error bars. For those points in which the vertical error bars are not visible, the errors were less than the height of the symbol used. viable. This same inverse relationship between lysosomal cystine content and cell survival was also found for normal human fibroblasts (Fig. 1B), suggesting that CDME increases lysosomal cystine levels, leading to lysosomal rupture and cell death. Since lysosomes from cystinotic fibroblasts are defective in cystine transport, incubating cystinotic fibroblasts with an appropriate concentration of CDME should result in a continual loading of cystine into their lysosomes without any means for cystine escape, causing the cystinotic lysosomes to swell and eventually burst. In contrast, the functional lysosomal cystine transport system of normal cells could export enough cystine to prevent or delay lysosomal rupture. To test this hypothesis, cystinotic and normal human fibroblasts were exposed for varying periods of time to various concentrations of CDME added to their culture medium and then cell viability was measured by several different methods as described in Materials and Methods. Based on the ${ }^{14} \mathrm{C}$-incorporation assay, none of the $2 \times 10^{6} \mathrm{DFL}$ cystinotic fibroblasts and only $0.03 \%$ of GM0090 cystinotic fibroblasts survived exposure to 2 $\mathrm{mM}$ CDME for $20 \mathrm{~min}$, whereas $68 \%$ of normal fibroblasts and $34 \%$ of cystinotic heterozygotes remained viable under these same conditions (Table 1). When normal fibroblasts are replated following exposure to $2 \mathrm{mM}$ CDME for $20 \mathrm{~min}$, they display a doubling rate that is very similar to that of normal fibroblasts not exposed to CDME (Fig. 2), indicating that fibroblasts that survive CDME treatment continue to grow at a normal rate.

An assay of the colony-forming ability of fibroblasts further demonstrated the extremely cytotoxic effect of CDME on cystinotic cells. When control SV40-transformed cystinotic cells (GM02894) are trypsinized, approximately $20 \%$ of the cells survive trypsinization to form colonies during a subsequent 7 - to 10-day culture period (Table 2). No colonies form, however, if 
Table 1. Ability of Normal or Cystinotic Fibroblasts to Incorporate $\left[{ }^{14} \mathrm{C}\right]$ Amino Acids following Exposure to 2 mM Cystine Dimethyl Ester ${ }^{a}$

\begin{tabular}{lc}
\hline \multicolumn{1}{c}{ Cell line } & $\begin{array}{c}{\left[{ }^{14} \mathrm{C}\right] \text { Amino acid }} \\
\text { incorporation } \\
\text { (\% of untreated control) }\end{array}$ \\
\hline GM0010 (normal) & $67.5 \pm 6.1$ \\
UM004 (heterozygous) & $34.0 \pm 1.2$ \\
DFL (cystinotic) & $0.0 \pm 0$ \\
GM0090 (cystinotic) & $0.028 \pm 0.02$ \\
\hline
\end{tabular}

${ }^{a}$ Confluent monolayers of the given fibroblast cell lines were incubated with $2 \mathrm{mM}$ CDME for $20 \mathrm{~min}$, then washed, trypsinized, and replated in complete medium containing $\left[{ }^{14} \mathrm{C}\right]$ amino acids. After $20 \mathrm{~h}$, plates were washed three times with PBS, cells were harvested, and cell-associated radioactivity measured with a scintillation counter. Results are expressed as a percentage of the radioactivity incorporated by control plates that were not treated with CDME.

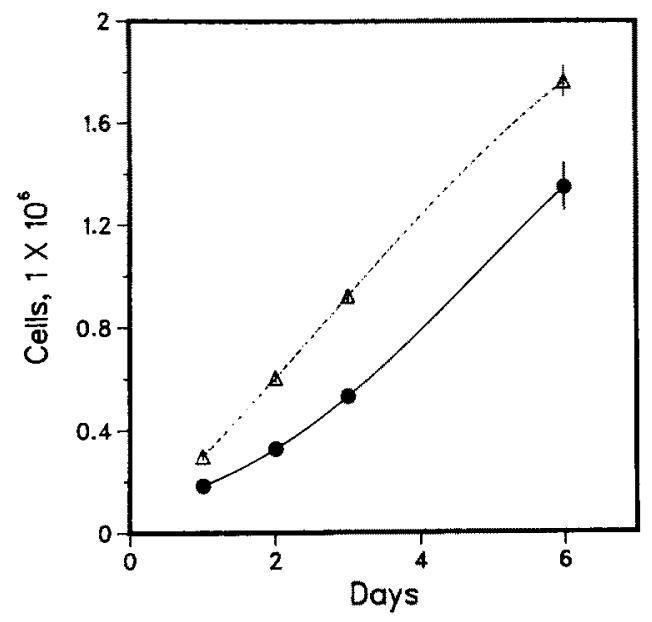

Fig. 2. Growth of normal human fetal fibroblasts (GM0010A) in cell culture following exposure to $2 \mathrm{mM}$ CDME for $20 \mathrm{~min}$. Confuent monolayers of normal human fetal fibroblasts (GM0010A) were washed and then incubated for $20 \mathrm{~min}$ in culture medium containing either $2 \mathrm{mM} \mathrm{CDME}(\Delta-\Delta)$ or not containing $2 \mathrm{mM}$ CDME (-). Monolayers were then washed, trypsinized, cells counted, and equal numbers of cells replated into $100-\mathrm{mm}$ culture dishes. Cells were incubated at $37^{\circ} \mathrm{C}$ and, at the indicated times, plates were harvested by trypsinization and cell numbers were measured with a Coulter counter. The results shown are an average of duplicate determinations with the variation indicated by the vertical error bars. For those points in which the vertical error bars are not visible, the errors were less than the height of the symbol used.
Table 2. Colony-Forming Ability of Cystinotic

Fibroblasts following Exposure to Cystine Dimethyl Ester

\begin{tabular}{rcc}
\hline & \multicolumn{2}{c}{ Colony forming ability $(\%)$} \\
\cline { 2 - 3 } CDME & $\begin{array}{c}\text { 10 min CDME } \\
\text { exposure }\end{array}$ & $\begin{array}{c}\text { 20 min CDME } \\
\text { exposure }\end{array}$ \\
\hline $0 \mathrm{mM}$ & $17.1 \pm 2.1$ & $22.5 \pm 7.2$ \\
$1.0 \mathrm{mM}$ & $9.0 \pm 3.4$ & $1.2 \pm 1.2$ \\
$1.5 \mathrm{mM}$ & $4.8 \pm 2.7$ & $0.01 \pm 0.01^{*}$ \\
$2.0 \mathrm{mM}$ & $0.15 \pm 0.17^{*}$ & $0.00 \pm 0^{*}$ \\
\hline
\end{tabular}

${ }^{\circ}$ Confluent $60-\mathrm{mm}$ plates of an SV40-transformed cystinotic fibroblast cell line (GM02894) were incubated for 10 or $20 \mathrm{~min}$ in cell culture medium containing $10 \% \mathrm{fe}$ tal calf serum and cystine dimethyl ester of the indicated concentration. Following exposure to CDME, plates were washed, trypsinized, a portion of the cells were counted, and the remaining cells were plated at a low cell density in cell culture medium containing $10 \%$ fetal bovine serum. Cell cultures were incubated for $7-10$ days at $37^{\circ} \mathrm{C}$, at which time individual colonies were visualized by staining plates with $0.3 \%$ crystal violet in $20 \%$ ethanol. The colony-forming ability is expressed as the number of colonies observed divided by the number of cells plated times $100 \%$. The results are an average of two separate experiments for those indicated with an asterisk, which are an average of three experiments.

SV40-transformed cystinotic cells are exposed to $2 \mathrm{mM}$ CDME for $20 \mathrm{~min}$ prior to trypsinization (Table 2). Exposure of fibroblasts to $2 \mathrm{mM}$ CDME for times longer than 20 min or treatment for $20 \mathrm{~min}$ with CDME concentrations greater than $3 \mathrm{mM}$ was found to be strongly cytotoxic to both normal and cystinotic fibroblasts (data not shown). Apparently, under these conditions, cystine transport by normal fibroblast lysosomes is not able to export cystine faster than it forms within lysosomes, thus leading to eventual lysosomal rupture. On the other hand, using conditions that load cystine into lysosomes at a slower rate, such as incubating fibroblasts with concentrations of CDME less than 2 $\mathrm{mM}$, results in good retention of cell viability for normal fibroblasts but also partial retention of cell viability of cystinotic fibroblasts. Thus, exposure to $2 \mathrm{mM}$ CDME for $20 \mathrm{~min}$ appears to provide the optimal conditions for good retention of cell viability of normal 
Fig. 3. Survival of nonfetal normal and cystinotic fibroblasts in CDME. Normal and cystinotic nonfetal fibroblast cell lines were incubated in culture medium containing 2 $\mathrm{mM}$ CDME for $30 \mathrm{~min}$. Plates were then washed twice with PBS, cells were trypsinized, and cell viability was measured by the $4-h$ attachment assay as described in Materials and Methods.

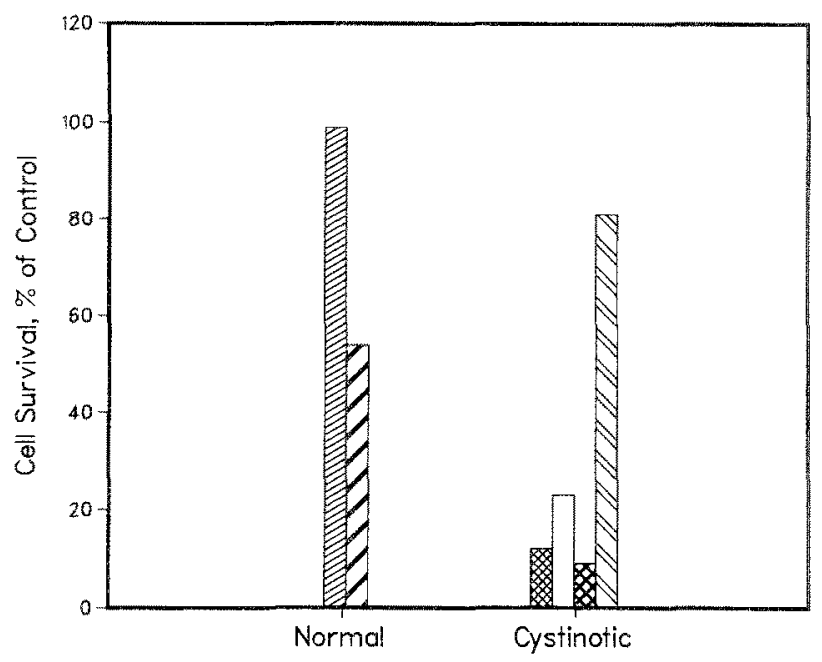

fibroblasts yet yielding nearly complete destruction of cystinotic fibroblasts.

Cell viability was also assessed by counting the number of fibroblasts harvested after a 4 -h attachment assay. This method provides rapid quantitation of the degree of overall cell viability and was used in experiments to determine cell viability of $10-12$ different fibroblast cell lines. One possible limitation of this method, however, is that it does not accurately discriminate differences in cell viability when only a small number of cells remain on a plate. Thus, Coulter counting accurately measures whether $50 \%$ or $5 \%$ of the cells survive CDME treatment, but it does not appear to accurately discrimi- nate whether $0.001 \%$ or $2 \%$ of the cells survive CDME treatment, as does the colony forming assay or the method of $\left[{ }^{14} \mathrm{C}\right]$ amino acid incorporation.

It became apparent after measuring the cytotoxic effects of exposing fibroblasts to 2 $\mathrm{mM}$ CDME for $20 \mathrm{~min}$ that fetal fibroblasts generally were more sensitive to CDME killing than nonfetal lines. Thus, two cystinotic fetal fibroblast cell lines, DFL and GM0090, were nearly completely killed by 2 $\mathrm{mM}$ CDME for $20 \mathrm{~min}$ (Table 1), whereas some cystinotic nonfetal fibroblast lines displayed partial retention of viability when exposed to $2 \mathrm{mMCDME}$ for $20 \mathrm{~min}$ (data not shown). If the time of exposure to $2 \mathrm{mM}$
Fig. 4. Survival of normal and cystinotic SV40-transformed fibroblasts and the nontransformed obligate heterozygous parents of that cystinotic line. Fibroblasts were incubated in culture medium containing $1.5 \mathrm{mM}$ CDME for $20 \mathrm{~min}$. Plates were then washed twice with PBS, cells were trypsinized, and cell viability was measured by the 4-h attachment assay as described in Materials and Methods.

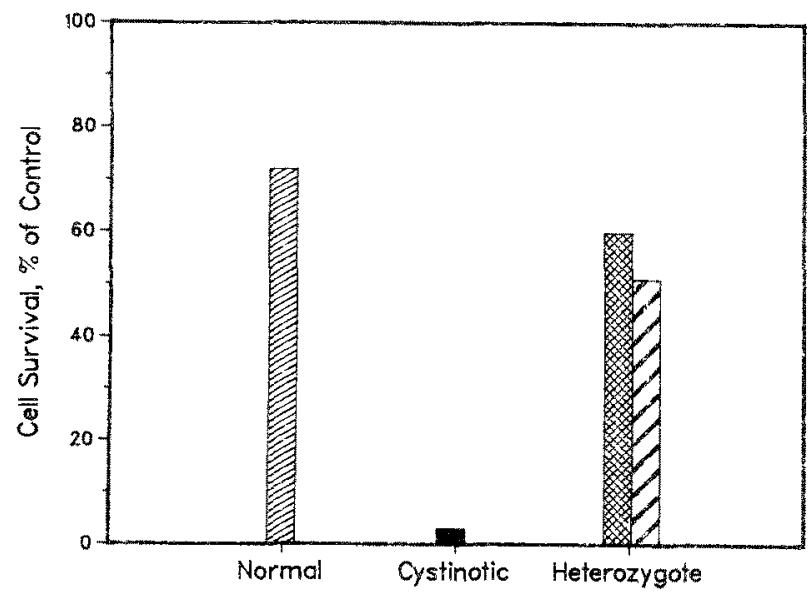


CDME was increased from $20 \mathrm{~min}$ to $30 \mathrm{~min}$, however, then the majority of the cystinotic child lines displayed $>85 \%$ cell death. In contrast, nonfetal normal fibroblast lines demonstrated good retention of cell viability (Fig. 3). Thus, it is important to optimize the CDME selection method for the cell types used, such that child cystinotic fibroblast lines require a longer period of exposure to CDME than fetal lines in order to achieve the desired cytotoxic effect of CDME. No difference in sensitivity between fibroblast cell lines originating from skin or lung tissue has been noted.

Since SV40-transformed cell lines display an infinite life-span and are particularly useful for DNA transfection studies, we further evaluated the cytotoxicity of CDME upon SV40-transformed normal and SV40transformed cystinotic fibroblasts using the 4-h cell attachment assay. SV40-transformed normal human fibroblasts poorly survived exposure to $2 \mathrm{mM}$ CDME for $20 \mathrm{~min}$. However, if the CDME concentration was reduced to $1.5 \mathrm{mM}$, then the normal SV40transformed fibroblasts displayed good retention of cell viability, whereas the cystinotic SV40-transformed fibroblasts did not survive (Fig. 4). The colony-forming ability assay (Table 2) also demonstrated no significant survival of SV40-transformed cystinotic fibroblasts after exposure to $1.5 \mathrm{mM}$ CDME for $20 \mathrm{~min}$.

The CDME method described in this paper can be applied to selectively ablate cystinotic fibroblasts yet retain good viability of normal fibroblasts. As indicated, the technique must be optimized for the cell lines used since fetal, nonfetal, and SV40transformed lines display differences in their sensitivity to CDME killing. Although rare, we have found one cystinotic cell line that appears resistant to CDME killing (Fig. 2) and one normal fetal fibroblast line that is extremely sensitive to the cytotoxic effects of CDME. Nonetheless, using cell lines pretested for their sensitivity to CDME (e.g.,
SV40-transformed cystinotic fibroblasts), the CDME selection method can provide an extremely useful means for isolating cystinotic fibroblasts stably transformed to the normal phenotype following transfection of cystinotic fibroblasts with normal human genomic DNA or cDNA.

\section{ACKNOWLEDGMENTS}

This work was supported by grant DK25548 from the National Institutes of Health.

\section{LITERATURE CITED}

1. Gahl, W., Renlund, M., and Thoene, J. (1989). In The Metabolic Basis of Inherited Disease, 6th ed. (eds.) Scriver, C.R., Beaudet, A.L., Sly, W.S., and Valle, D. (McGraw-Hill, New York), pp. 2619 2641.

2. Liu, P.K., Goudreau, B., and Hsu, G.S. (1989). Somat. Cell Mol. Genet. 15:331-344.

3. Reeves, J.P. (1979). J. Biol. Chem. 254:8914-8921.

4. Goldman, R., and Kaplan, A. (1973). Biochim. Biophys. Acta 318:205-216.

5. Goldman, R. (1973). FEBS Lett. 33:208-212.

6. Jonas, A.J., Greene, A.A., Smith, M.L., and Schneider, J.A. (1982). Proc. Natl. Acad. Sci. U.S.A. 79:4442-4445.

7. Pisoni, R.L., Thoene, J.G., and Christensen, H.N. (1985). J. Biol. Chem. 260:4791-4798.

8. Schneider, J.A., Rosenbloom, F.M., Bradley, K.H., and Seegmiller, J.E. (1967). Biochem. Biophys. Res. Commun. 29:527-531.

9. Schulman, J.D., Bradley, K.H., and Seegmiller, J.E. (1969). Science 166:1152-1154.

10. Schulman, J.D., and Bradley, K.H. (1972). In Cystinosis, (U.S. Department of Health, Education and Welfare (NIH) 72-249. Washington, D.C.), pp. 111-145.

11. Smith, M.L., Greene, A.A., Schneider, J.A., Pisoni, R.L., and Christensen, H.N. (1989). Methods Enzymol. 174:154-162.

12. Gahl, W.A., Bashan, N., Tietze, F , Bernardini, I., and Schulman, J.D. (1982). Science 217:1263-1265.

13. Gahl, W.A., Tietze, F., Bashan, N., Steinherz, R., and Schulman, J.D. (1982). J. Biol. Chem. 257:95709575

14. Gabl, W.A., Tietze, F., Bashan, N., Bernardini, I, Raiford, D., and Schulman, J.D. (1983). Biochem. J. 216:393-400.

15. Oshima, R.G., Willis, R.C., Furlong, C.E., and Schneider, J.A. (1974). J. Biol. Chem. 249:60336039. 